Original Article

\title{
The Role of Radiology (X-Ray versus Computed Tomography) in Medicolegal Cases Presented at a Tertiary Care Hospital in Pakistan
}

\author{
Rabail Altaf', Abdul Razaque ${ }^{2}$, Moshin Hussain ${ }^{2}$, Asghar Ali Memon ${ }^{3}$, Imran Khan Memon ${ }^{4}$ \\ Nargis Pirya ${ }^{5}$, Abd-ur-Rehman ${ }^{6}$, Kiran Abbas ${ }^{7}$ \\ ${ }^{1}$ Department of Forensic Medicine, Gambat Medical College, Gambat, ${ }^{2}$ Department of Radiology, Pir \\ Abdul Qadir Shah Jeelani Institute of Medical Sciences (PAQS-JIMS), Gambat, ${ }^{3}$ Department of \\ Community Medicine, Gambat Medical College, Gambat, ${ }^{5}$ Department of Biochemistry, Gambat Medical \\ College, Gambat, Sindh. ${ }^{4}$ Department of Radiology, Ghulam Muhammad Mahar Medical College, Sukkar \\ ${ }^{6}$ Department of Medical ICU, Usman Memorial Hospital, ${ }^{7}$ Department of Medicine, Jinnah Postgraduate \\ Medical Center, Karachi - Pakistan
}

\section{ABSTRACT}

Objectives: A prospective observational study was aimed to assess the role of plain radiographs and computed tomography in detecting head injuries presented at the medicolegal office at the Forensics and Radiology Departments, Gambat Medical Hospital, Sindh.

Material and Methods: All cases referred from the Medicolegal Office (MLO) with head injury were included. All victims underwent $X$-ray head and computed tomography skull was done with 1 or $1.5 \mathrm{~cm}$ thick axial sections without administration of intravenous contrast. The radiological reports of X-ray head and CT scans were documented and comparatively evaluated.

Results: Mean age was $38.63 \pm 3.91$ years. In 51 (45.13\%) cases, X-ray was able to detect skull fracture, while CT scan detected 64(56.64\%) skull fractures. There were 54 (84.3\%) true positives, 3 (2.6\%) false positives, $10(8.8 \%)$ false negatives, and $40(40.7 \%)$ true negatives. The accuracy of X-ray to detect skull fracture was $88.50 \%$.

Conclusion: X-ray had a sensitivity and specificity of $84.38 \%$ and $93.88 \%$, respectively. It is a reliable tool to detect skull fractures in victims of assault in comparison with CT scans. X-ray is also associated with low dose radiation exposure as compared with $\mathrm{CT}$ scan which delivers 70 times more exposure than the former.

Keywords: Computed Tomography, Forensic Medicine, Head Injury, Radiology, Trauma, X Ray.

Corresponding Author: Rabail Altaf

Forensic Medicine department, Gambat Medical College,

Gambat, Sindh - Pakistan

Email: rabailmuslim@gmail.com
Date of Submission: 03-05-2021

Date of Revision: 13-06-2021

Date of Online Publishing: 30-06-2021

Date of Print: 30-06-2021

DOI: 10.36552/pjns.v25i2.534 


\section{INTRODUCTION}

The Head is an uncovered and most prominent part of the body, which encloses the most valuable organ i.e. the brain. The brain is susceptible to injury due to accidental or intentional trauma. A head injury is the most common cause of death throughout the world. ${ }^{2}$ In Pakistan, mortality associated with a head injury is $15 \%$ and the incidence is 81 per 100 thousand populations. ${ }^{3}$

The commonly practiced Qisas and Diyat Act categorizes head injuries into six types with respect to the depth and severity of trauma. ${ }^{4}$ Shajjah-i-Khafifah is the most minor injury defined as a superficial soft tissue injury which does not expose the bone, while Shajjah-iDamighah is the most severe form and characterized by the rupture of the dural membrane. The characteristic features of each of these types of injury help in determining the extent of the injury and the evaluation of punishment for the offender. ${ }^{4,5}$

Medico-legal officers utilize radiological evidence to study the trauma to the skull. Though CT scan and a plain radiograph are considered to be the most significant radiological scan for the evaluation of head trauma, their benefits in medico-legal investigations is still not established. ${ }^{6,7}$

The extent of physical damage is equivalent to the severity of the injury. A low Glasgow coma scale (GCS) score is strongly associated with a severe injury causing immense damage. However, in medico-legal cases, this is not evaluated. ${ }^{8,9}$

Despite the evident technological advancements in radiology, its role in forensics is still debatable and requires accreditation by the international scientific communities. The varying settings and law systems make it challenging to establish a similar pattern of radiological assessments in forensic organizations.
Therefore, due to the lack of accurate medical evidence for medico-legal certification of a head injury and the comparison of the severity of injury in terms of radiology and clinical investigation forms the present study was undertaken.

The objective of the current study was to highlight the role of radiology (X-ray versus CT Scan) in detecting head skull fractures in victims of severe head injuries presenting to the Medicolegal Department, Gambat, Sukkur Pakistan.

\section{MATERIAL AND METHODS}

\section{Study Design \& Study Settings}

A prospective observational study was conducted between January 2020 to December 2020 for a period of 12 months. The study was a collaborative effort of both the Forensics Department and Radiology Department, Gambat Medical Hospital. A non-probability consecutive sampling method was applied to enrolled patients/victims to the study. Ethical approval was obtained prior to the initiation of data collection. Informed written consent was also secured from the participants.

\section{Inclusion Criteria}

All cases referred from the Police Department or Medicolegal Office (MLO) with a head injury for medical certification were eligible to take part in the study, irrespective of age and gender with a history of assault.

\section{Exclusion Criteria}

Injuries associated with major destruction of skull bone (defined by multiple comminuted fractures) with unknown details of the weapon used and those who were dead before arrival into the hospital was excluded from the study. All nonmedico legal cases of head injury as a result of a 
fall or some accident were also excluded.

\section{Data Collection Tools \& Procedure}

The severity of the head injury is defined by Glasgow Coma Scale (GCS). Patients with a GCS score of 8 or below were defined as severe injuries whereas, patients with a GCS score of 912 is defined as moderate injuries. GCS scores above 12 were labeled as mild injuries.

All victims underwent X-ray head and Computed tomography skull was done with 1 or $1.5 \mathrm{~cm}$ thick axial sections without administration of intravenous contrast. The report findings were documented by experienced radiologists with 5 years of experience or more. Head copy and console images were read at brain and bone settings.

All sociodemographic data including gender, age, occupation, education, residence, time of injury, the weapon used during the assault, and other clinical data were recorded in a predefined proforma. The radiological reports of X-ray head and $\mathrm{CT}$ scan were documented and comparatively evaluated.

\section{Data Analysis}

All data was entered and analyzed using SPSS statistical software version 24.0. For comparative analysis between X-ray and Ct-scan, sensitivity, specificity, the positive predictive value (PPV), negative predictive value (NPV) and accuracy were assessed via a 2 by 2 contingency table. CT scan was placed as gold standard while comparing with $\mathrm{X}$-ray. All continuous variables were presented as mean and standard deviation while all categorical data were presented as frequency and percentages. A $p$-value of $<0.05$ was set as the cut-off value for significance.

\section{RESULTS}

\section{Sociodemographic Characteristics of Victims}

The mean age (standard deviation) was $38.63 \pm$ 
3.91 years. There were 66 (58.4\%) male patients and 47 (41.6\%) female patients. The mean weight and height of victims were $57.84 \pm 14.1 \mathrm{~kg}$ and $147.66 \pm 26.7 \mathrm{~cm}$, respectively. See Table 1 .

Table 1: Demographics of Victims of Head Trauma in Study Population.
Mean Age \pm SD

Gender Male Female

Mean Weight \pm SD

Mean Height \pm SD

Mean Body Mass Index \pm SD
$38.63 \pm 3.91$

$66(58.4 \%)$

$47(41.6 \%)$

$57.84 \pm 14.1$

$147.66 \pm 26.7$

$23.26 \pm 2.54$

\section{Diagnostic Role of X-Ray versus}

\section{Computed Tomography Scan}

All 113 patients who fulfilled the eligibility criteria underwent an X-ray and CT scan of the skull for diagnosis of head skull fractures. In 51 (45.13\%) cases, X-ray was able to detect skull fracture while CT scan detected 64 (56.64\%) skull fractures. Xray missed $6.2 \%$ skull fractures. See Table 2.

Table 2: Comparison of fracture skull labelled in Xray and $C T(n=113)$.

\begin{tabular}{|c|c|c|c|c|}
\hline $\begin{array}{l}\text { Investi- } \\
\text { gation }\end{array}$ & $\begin{array}{l}\text { No. of } \\
\text { cases }\end{array}$ & $\begin{array}{c}\text { Fracture } \\
\text { Seen }\end{array}$ & $\%$ & $\begin{array}{c}\text { \% Missed on } \\
\text { X-ray }\end{array}$ \\
\hline X-ray & 113 & 57 & $50.44 \%$ & $6.20 \%$ \\
\hline $\mathrm{CT}$ & 113 & 64 & $56.64 \%$ & - \\
\hline
\end{tabular}

\section{Diagnostic Accuracy of X-Ray Imaging in the Detection of Skull Injuries}

Table 3 shows the diagnostic value of $\mathrm{X}$-ray keeping $C T$ scans as the gold standard. It was found that the sensitivity and specificity of X-ray was $84.38 \%$ and $93.88 \%$, respectively. There were 54 (84.3\%) true positives, 3 (2.6\%) false positives, 10 (8.8\%) false negatives, and 40 (40.7\%) true negatives. The accuracy of X-ray to detect skull fracture was $88.50 \%$.
Table 3: Statistical Evaluation of X-Ray keeping CT Scan as Gold standard.

\begin{tabular}{|lc|} 
Variable & Result \\
\hline True Positive & $54(47.7 \%)$ \\
False Positive & $3(2.6 \%)$ \\
False Negative & $10(8.8 \%)$ \\
True Negative & $46(40.7 \%)$ \\
\hline \multicolumn{2}{|l}{} \\
\hline Sensitivity & $84.38 \%$ \\
Specificity & $93.88 \%$ \\
Positive Likelihood Ratio & 13.78 \\
Negative Likelihood Ratio & 0.166 \\
Disease prevalence & $37.97 \%$ \\
Positive Predictive Value & $94.74 \%$ \\
Negative Predictive Value & $82.14 \%$ \\
Accuracy & $88.50 \%$ \\
Kappa & 0.770 \\
\hline
\end{tabular}

\section{DISCUSSION}

Traumatic head injuries are defined as any injury to the skull, meninges, or the brain. ${ }^{10}$ Head trauma may result from road traffic accidents or a fall. ${ }^{11}$ Fractures due to accidental or nonaccidental causes result in physical damage to the bones of the skull, and can be studied by means of imaging techniques, particularly $\mathrm{CT}$ scans and $\mathrm{X}$ rays. $^{12}$ In medico-legal cases, head traumas may occur due to accidents or abuse. In such cases, imaging plays a major role in the assessment and evaluation of individuals who may have abusive head traumas since clinical features may not be specific to the cause of injury. ${ }^{13}$ A study by Sidpra et al. studied the type of skull fractures resulting from abuse and reported $33 \%$ of skull fractures to be due to simple linear fractures of the parietal bone, while stellate fractures of the parietal and occipital bone comprised $29 \%$ and $10 \%$ of fractures respectively. ${ }^{14}$

In the present study, X-ray had a sensitivity and specificity of $84.38 \%$ and $93.88 \%$, respectively. The accuracy of X-ray to detect skull fracture was $88.50 \%$, making it a moderately reliable tool to detect skull fractures in victims of assault in comparison with CT scan which is considered as the gold standard for the diagnosis 
of head injury. In contrast to the current study, Chawla et al, revealed that when compared with the CT scan, X-ray was unable to detect 11.9 percent of head fractures thus claiming that X-ray had little role in the detection of skull fractures compared with CT scan and autopsy. ${ }^{15}$ In comparison, we had a much lower rate of missed skull fractures. In deceased patients, an autopsy is considered as a more definitive approach for the identification of skull fractures, as reported by Anand et al. ${ }^{16}$ and Goyal et al. ${ }^{17}$

However, in living patients, detection of fractures is more challenging. In the present study, the use of CT scans and X-rays was evaluated in patients suffering from head trauma. Our findings were consistent with the study by Chawla et al., which reported that CT scans were superior to X-rays in the evaluation of skull fractures in medico-legal cases. The study found that CT scans were $85.4 \%$ sensitive and $100 \%$ specific in the identification of fractures in medico-legal cases. ${ }^{18}$

In contrast to our findings, a study by Spies et al, reported that the use of $X$-rays had a sensitivity of only $22.3 \%$ as compared to CT scan which was found to be $47.3 \%$ sensitive. ${ }^{19}$ Studies in the past have reported lower sensitivity of CT scans as compared to the present study, which may indicate advancements in radiological techniques or the involvement of more experienced radiologic consultants.

Weak diagnostic potential of $\mathrm{X}$-rays was highlighted in the study by Korduke and Singh. The study identified the greater efficacy of CT scans over X-rays, by reporting that $82.1 \%$ of their study population who had received $X$-rays for the identification of fractures required an additional CT scan to confirm the diagnosis. ${ }^{20}$ This indicates that the CT scan is a better imaging technique that allows for the accurate diagnosis and efficient management of the case. This was supported by the findings of the literature analysis by Baglivo et al. which reported CT scans to be the principal imaging technique for the management of traumatic injury. ${ }^{21}$

A study by Eames reported that the results of a CT scan closely matched the accuracy of an autopsy, and is inarguably the best-suited alternative to autopsy in most medico-legal cases. $^{22}$ Thus, in cases where an autopsy is not the viable option for the evaluation of fractures in medicolegal cases, CT scans are the preferred replacement. There is a need for further research which would aim to standardize postmortem CT scan training and enhance the resolution of the images obtained.

Patients, particularly women, were reluctant to discuss the cause of trauma to their heads thereby making it difficult to identify the source of harm. The study was further limited due to missing data for some of the patients. Due to these reasons, it was difficult to estimate the actual frequency of head trauma due to medicolegal causes.

\section{CONCLUSION}

A plain radiograph was able to diagnose skull fractures reliably with a sensitivity and specificity of $84.38 \%$ and $93.88 \%$, respectively. It has an accuracy of $88.50 \%$, making it a moderately reliable tool to detect skull fractures in victims of assault in comparison with CT scans. X-ray is associated with low dose radiation exposure as compared with CT scan which delivers 70 times more exposure than the former. Moreover, the contrast used in CT scans can have complications. Therefore, it is advocated to keep X-rays as the first line of investigation in victims with head trauma. In case of a complicated injury, a CT scan should be advised.

\section{REFERENCES}

1. Deans KJ, Minneci PC, Lowell W, Groner JI. Increased morbidity and mortality of traumatic brain injury in victims of non-accidental trauma. Journal of Trauma and Acute Care Surgery, 2013; 75 (1): 157-60. 
2. Sohail S, Qureshi SR. Application of qisas and diyat act's terms for reporting in current forensic radiology practice. Journal of the College of Physicians and Surgeons-Pakistan: JCPSP. 2007; 17 (7): 402-405.

3. Yousfani GM, Sohail S, Memon MU. Radiological Appraisal of Moderate to Severe Head Injury \pm Medicolegal Implications. JLUMHS. 2010; 9 (03): 121-124.

4. Sohail S, Qureshi SR. Application of qisas and diyat act's terms for reporting in current forensic radiology practice. Journal of the College of Physicians and Surgeons - Pakistan: JCPSP. 2007; 17 (7): 402-405.

5. Vakilian A, Farahmand $H$, Sharifi-Razav A, Tajik F, Najmaddini M. Epidemiological, Clinical and Radiological Characteristics of Patients with Head Trauma. Internal Medicine and Medical Investigation Journal, 2017; 2 (1): 7-14.

6. Sameer C, Joshi HS, Gaurav J, Kashmir S. Outcome of head injury patients based on computed tomography (CT) scan findings in a Tertiary Care Hospital-A cross-sectional study. IJCMR. 2016; 3 (2): 610-612.

7. Kaye AH. Head injuries. Textbook of Surgery, 2019 Dec. 18: 481-92.

8. Mossman D, Bowen MD, Vanness DJ, Bienenfeld D, Correll T, Kay J, et al. Quantifying the accuracy of forensic examiners in the absence of a "gold standard". Law and Human Behavior. 2010; 34 (5): 402-17.

9. Sharma R, Murari A. A comparative evaluation of CT scan findings and post mortem examination findings in head injuries. Indian Internet Journal of Forensic Medicine \& Toxicology, 2006; 4 (2).

10. Ismail A, Azez E. Role of computed tomography (CT) in diagnosis of urgent head trauma in adult. Romanian Journal of Neurology, 2018; 17 (2): 8497.

11. Mohamed Refaat RM, Haroun MR, El Din $S$, Hussein AY. Medico Legal Aspects of Traumatic Head Injuries in Benha University Hospital (Prospective Analytical Study). The Egyptian Journal of Forensic Sciences and Applied Toxicology, 2019; 19 (4): 119-45.
12. Onwuchekwa RC, Echem RC. An epidemiologic study of traumatic head injuries in the emergency department of a tertiary health institution. Journal of Medicine in the Tropics, 2018; 20 (1): 24-29.

13. Wright JN. CNS injuries in abusive head trauma. American Journal of Roentgenology, 2017; 208 (5): 991-1001.

14. Sidpra J, Ong J, Birch W, Mankad K. Skull fractures in abusive head trauma: a single centre experience and review of the literature. Child's Nervous System, 2020; 1-1: 919-929.

15. Chawla H, Malhotra R, Yadav RK, Griwan MS, Paliwal PK, Aggarwal AD. Diagnostic Utility of Conventional Radiography in Head Injury. J Clin Diagn Res. 2015; 9 (6): TC13-5.

16. Menon A, Kanchan T, Rao NG. Skull fractures in fatal head injuries-a comparative analysis of CT and autopsy findings. Journal of Forensic Medicine \& Toxicology, 2012; 29 (1): 55.

17. Goyal M, Goyal R, Kochar SR, Goel MR. Fracture of the temporal bone: A tomographic $V / S$ autopsy study. Journal of Indian Academy of Forensic Medicine, 2007; 29 (2): 76-9.

18. Chawla H, Yadav RK, Griwan MS, Malhotra R, Paliwal PK. Sensitivity and specificity of CT scan in revealing skull fracture in medico-legal head injury victims. The Australasian Medical Journal, 2015; 8 (7): 235.

19. Spies AJ, Steyn $M$, Brits D. A comparison of computed tomography, X-ray and Lodox ${ }^{\circledR}$ scans in assessing pediatric skull fractures using piglets. Journal of Forensic Sciences, 2021; 66 (2): 470-8.

20. Korduke $\mathrm{N}$, Singh $\mathrm{T}$. Imaging of midface fractures-a retrospective study. Imaging, 2019; 132 (1498): 60-68.

21. Baglivo M, Winklhofer $S$, Hatch GM, Ampanozi G, Thali MJ, Ruder TD. The rise of forensic and postmortem radiology-analysis of the literature between the year 2000 and 2011. Journal of Forensic Radiology and Imaging, 2013; 1 (1): 3-9.

22. Eames T. Computed Tomography in Medicolegal Death Investigation: A Critical Review. Available: https://pdxscholar.library.pdx.edu/cgi/viewcontent. cgi?article $=2138 \&$ context $=$ honorstheses 


\section{Additional Information}

Disclosures: Authors report no conflict of interest.

Ethical Review Board Approval: The study was conformed to the ethical review board requirements.

Human Subjects: Consent was obtained by all patients/participants in this study.

Conflicts of Interest:

In compliance with the ICMJE uniform disclosure form, all authors declare the following:

Financial Relationships: All authors have declared that they have no financial relationships at present or within the previous three years with any organizations that might have an interest in the submitted work.

Other Relationships: All authors have declared that there are no other relationships or activities that could appear to have influenced the submitted work.

AUTHORS CONTRIBUTIONS

\begin{tabular}{|l|l|l|}
\hline Sr.\# & Author's Full Name & Intellectual Contribution to Paper in Terms of: \\
\hline 1. & Rabail Altaf & Study design and methodology. \\
\hline 2. & Abdul Razaque & Paper writing and data calculations. \\
\hline 3. & Moshin Hussain & Data collection and calculations. \\
\hline 4. & Imran Khan Memon & Analysis of data and interpretation of results etc. \\
\hline 5. & Asghar Ali Memon, Abd-ur-Rehman & Literature review and referencing. \\
\hline 6. & Kiran Abbas, Nargis Pirya & Analysis of data and quality insurer. \\
\hline
\end{tabular}

